\title{
DESENVOLVIMENTO VEGETATIVO DO PEPINO ENXERTADO IRRIGADO COM ÁGUA SALINA ${ }^{1}$
}

\author{
Marcos Vinícius Folegatti; Flávio Favaro Blanco3,4 \\ ${ }^{2}$ Depto. de Engenharia Rural - USP/ESALQ, C.P. 9 - CEP: 13418-900 - Piracicaba, SP. \\ ${ }^{3}$ Pós-Graduando do Depto. de Engenharia Rural - USP/ESALQ. \\ ${ }^{4}$ Bolsista FAPESP. \\ *Autor correspondente <mvfolega@carpa.ciagri.usp.br>
}

\begin{abstract}
RESUMO: A salinização dos solos em ambiente protegido devido ao excesso de fertilizantes e falta de lixiviação tem resultado na redução da produtividade das culturas. Este trabalho teve o objetivo de avaliar os efeitos da irrigação com água salina no desenvolvimento vegetativo do pepino enxertado cultivado em ambiente protegido. Foram utilizadas águas de diferentes salinidades ( $\mathrm{S} 1=1,58 ; \mathrm{S} 2=3,08$ e $\mathrm{S} 3=5,13 \mathrm{dS} \mathrm{\textrm {m } ^ { - 1 }}$ ), lâminas de água de irrigação ( $L 0=1,00$ x ETc e $L 1=1,25$ x ETc) e freqüências de aplicação da lâmina $L 1$ ( $F 1=e m$ todas as irrigações e F2=quando a lâmina de água de irrigação acumulada em L0 atingia $100 \mathrm{~mm}$ ). Os resultados demonstraram que a altura das plantas, área foliar unitária e índice de área foliar foram afetados linearmente pela salinidade da água, não apresentando diferença para as diferentes lâminas e frequências de aplicação de L1.

Palavras-chave: Cucumis sativus, irrigação, salinidade, desenvolvimento vegetativo
\end{abstract}

\section{VEGETATIVE DEVELOPMENT OF GRAFTED CUCUMBER PLANTS IRRIGATED WITH SALINE WATER}

\begin{abstract}
Greenhouse soil salinization by excessive fertilization and lack of leaching has been a common cause of cucumber yield reduction in Brazil. The aim of this work was to evaluate the effects of irrigation with saline water on the vegetative development of grafted cucumber plants in a greenhouse. Three water salinities $\left(\mathrm{S} 1=1.58 ; \mathrm{S} 2=3.08\right.$ e S3=5.13 dS m $\left.{ }^{-1}\right)$, two irrigation water depths $\quad(\mathrm{L} 0=1.00 \times \mathrm{ETc}$ e L1=1.25 $\times$ ETc) and two application frequencies of $L 1$ (F1=in all irrigations and $F 2=$ when the irrigation water depth of $L 0$ reached 100 $\mathrm{mm}$ ) were used. Irrigation water depths and frequencies of $L 1$ were grouped and, therefore, the experimental design was in a factorial scheme $3 \times 3$, with randomized blocks. Results showed that plant height, unit leaf area and leaf area index were linearly affected by water salinity. No differences were observed for the various irrigation water depths and frequencies of $\mathrm{L} 1$ application.
\end{abstract}

Key words: Cucumis sativus, irrigation, salinity, vegetative development

\section{INTRODUÇÃO}

O cultivo de hortaliças em ambiente protegido tem crescido muito nos últimos anos devido à melhor qualidade do produto e ao menor risco quanto a fatores ambientais adversos. Entre as culturas mais exploradas em ambiente protegido no Estado de São Paulo encontram-se o pimentão, pepino, tomate, alface, entre outras (Trani et al., 1997). A cultura do pepino exige temperaturas altas para o bom desenvolvimento e produção, sendo bastante beneficiada sob este sistema de cultivo.

O consumo de água pelas plantas em ambiente protegido tem sido tema de muitos trabalhos, dada a importância que a irrigação assume sob esta condição de cultivo. Martínez-Raya \& Castilla (1989), estudando a evapotranspiração de pimentão em ambiente protegido, concluíram que a evaporação do tanque "Classe A", medida no interior da estufa, e o coeficiente de cultivo $(\mathrm{Kc})$ da FAO estimaram razoavelmente a evapotranspiração da cultura até 100 dias após o transplantio, utilizando um coeficiente de tanque $(\mathrm{Kp})$ igual a 1,0 e para períodos em que a temperatura foi superior a $10^{\circ} \mathrm{C}$. Resultados semelhantes foram obtidos por Castilla et al. (1990) para pepino, melão, melancia e feijão. Estes autores recomendam a utilização Kp igual a 1,0 quando o tanque é instalado no interior de estufas, independendo da cultura explorada.

Medeiros et al. (1997) determinaram a relação entre a evaporação medida em um tanque "Classe A" padrão e um tanque reduzido, para condições de estufa e estação meteorológica convencional. Com isso, independente do local de instalação, a evaporação do tanque "Classe A" pode ser estimada a partir da evaporação do tanque reduzido pela expressão:

$$
E C A=0,88 . E T R-0,03
$$

sendo ECA e ETR a lâmina de água evaporada $(\mathrm{mm})$ do tanque "Classe A" e do tanque reduzido, respectivamente.

Em experimento em ambiente protegido, Loomis \& Crandall (1977) verificaram que o consumo de água do pepino foi de, aproximadamente, 31 litros por planta para um período de cultivo de 60 dias. Os autores enfatizam que $\mathrm{K} \mathrm{Kc}$ da cultura foi muito superior ao da maioria das 
culturas, o que indica que, embora o pepino seja uma cultura que apresenta alta eficiência de utilização de água, grande quantidade de água é necessária no período de colheita para suprir as necessidades hídricas da planta.

A aplicação de fertilizantes via água de irrigação é prática comum nos cultivos protegidos e, especialmente quando realizada por meio de sistemas de irrigação eficientes, como é o caso do gotejamento, permite a otimização da utilização dos nutrientes pelas plantas. A fertirrigação do pepino em ambiente protegido pode proporcionar incrementos de produção acima de 100\% (Papadopoulos, 1999). Segundo Stanley \& Maynard (1990), o manejo da irrigação é importante não apenas para suprir as plantas de água, mas também para permitir a absorção dos nutrientes necessários para a otimização da produção. Considerando que a necessidade de nutrientes é variável de acordo com o estágio fisiológico da planta, o parcelamento da adubação torna-se necessário para garantir a absorção equilibrada e minimizar as perdas destes nutrientes por lixiviação e volatilização.

Aplicações excessivas de fertilizantes, utilização de água salina e o formato do bulbo molhado na irrigação por gotejamento, fazem com que haja acúmulo de sais na superfície do solo e na periferia do bulbo. Em cultivo protegido, com características mais intensivas de utilização do solo, a aplicação de fertilizantes e o manejo do solo e da irrigação devem ser realizados de forma adequada a fim de evitar o acúmulo excessivo e prejudicial de sais (Carrijo et al., 1999).

A forma de controlar o acúmulo de sais no solo é pela lixiviação, que pode ser proporcionada pela precipitação pluvial ou pela aplicação de uma lâmina de água de irrigação superior àquela requerida pela cultura, fazendo com que uma fração da água aplicada percole abaixo da zona radicular, lixiviando parte dos sais acumulados. Como a única fonte de água para as culturas em ambiente protegido é a água de irrigação, a aplicação de uma fração de lixiviação se faz necessária para que a salinidade do solo não ultrapasse o limite tolerado pela cultura, mesmo quando a água utilizada for de boa qualidade (Blanco \& Folegatti, 1999).

Cada espécie, e mesmo cultivares, toleram variavelmente à salinidade (Gorham, 1995), o que faz com que a necessidade e manejo da lixiviação de sais no solo seja específica para cada cultura. Ayers \& Westcot (1985) reportam que a salinidade máxima da água de irrigação para o pepino deve ser de 1,7 dS $\mathrm{m}^{-1}$. Porém, Chartzoulakis (1990) verificou que o número de frutos por planta e o peso médio dos frutos reduziram significativamente quando a salinidade da água de irrigação apresentou valores superiores a $1,3 \mathrm{dS} \mathrm{m}^{-1}$, sendo de $15,9 \%$ a redução de produtividade para cada unidade de salinidade acrescida na água de irrigação. Jones et al. (1989) verificaram que a área foliar e 0 crescimento das plantas de pepino em ambiente protegido reduziram quando a cultura foi irrigada

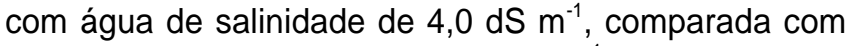
plantas irrigadas com água de $1,6 \mathrm{dS} \mathrm{m}^{-1}$.
De acordo com Lima et al. (1995), a enxertia do pepino sobre abóbora em ambiente protegido tem dado bons resultados e este porta-enxerto apresenta resistência aos fitonematóides. Oda (1995) afirma que a enxertia proporciona maior tolerância das culturas à salinidade, bem como aumenta a capacidade de absorção de água e nutrientes.

O objetivo deste trabalho foi avaliar os efeitos da salinidade da água de irrigação, lâmina de água de irrigação e manejo da lixiviação no desenvolvimento vegetativo do pepino enxertado, cultivado em ambiente protegido.

\section{MATERIAL E MÉTODOS}

O experimento foi conduzido na área experimental do Departamento de Engenharia Rural da Escola Superior de Agricultura "Luiz de Queiroz" - USP, no município de Piracicaba, SP, em Terra Roxa Estruturada. As características físicas do solo estão apresentadas na TABELA 1.

A cultura utilizada foi o pepino japonês (Cucumis sativus L.), cultivar Hokushin, enxertado sobre Cucurbita spp., híbrido Excite-lkki. O cultivar Hokushin apresenta crescimento indeterminado, frutos de coloração verde escura brilhante, aproximadamente $20 \mathrm{~cm}$ de comprimento e diâmetro médio de 2,5-3,0 cm. O início da colheita se dá aos 40-50 dias após o transplantio (DAT) e pode-se prolongar o período de colheita por até 120 dias (Cañizares, 1998).

A estufa utilizada apresentava área total de $110 \mathrm{~m}^{2}$, pé direito $2,8 \mathrm{~m}$, com sombrite nas laterais e nos fundos. As laterais possuíam cortinas que eram abertas pela manhã e fechadas no final da tarde e na ocorrência de chuvas para evitar que a água atingisse as parcelas experimentais. Foram construídos três canteiros de 16,65 $\mathrm{m}$ de comprimento e $1 \mathrm{~m}$ de largura, que foram divididos em 9 parcelas de $1,85 \mathrm{~m}$ de comprimento e $2 \mathrm{~m}$ de largura, totalizando 27 parcelas (Figura 1).

O transplantio foi realizado no dia $23 / 06 / 1999$, em filas duplas, no espaçamento de 0,7 m entre linhas, 0,4 $\mathrm{m}$ entre as plantas úteis e 1,3 $\mathrm{m}$ entre as filas duplas. As parcelas experimentais foram compostas de 10 plantas e separadas transversal e lateralmente até $0,8 \mathrm{~m}$ de profundidade por uma lâmina plástica de $0,15 \mathrm{~mm}$ de espessura para evitar o deslocamento lateral de água e sais entre as parcelas.

TABELA 1 - Granulometria e classe textural do solo em diferentes profundidades.

\begin{tabular}{|c|c|c|c|c|}
\hline \multirow[t]{2}{*}{ Profundidade } & \multicolumn{3}{|c|}{ Granulometria } & \multirow{2}{*}{$\begin{array}{l}\text { Classe } \\
\text { Textural }\end{array}$} \\
\hline & Areia & Silte & Argila & \\
\hline $\mathrm{m}$ & \multicolumn{3}{|c|}{---------- g kg ${ }^{-1}$----------- } & \\
\hline $0-0,2$ & 400 & 140 & 460 & Argiloso \\
\hline $0,2-0,4$ & 370 & 130 & 500 & Argiloso \\
\hline $0,4-0,6$ & 350 & 130 & 520 & Argiloso \\
\hline $0,6-0,8$ & 330 & 110 & 560 & Argiloso \\
\hline
\end{tabular}




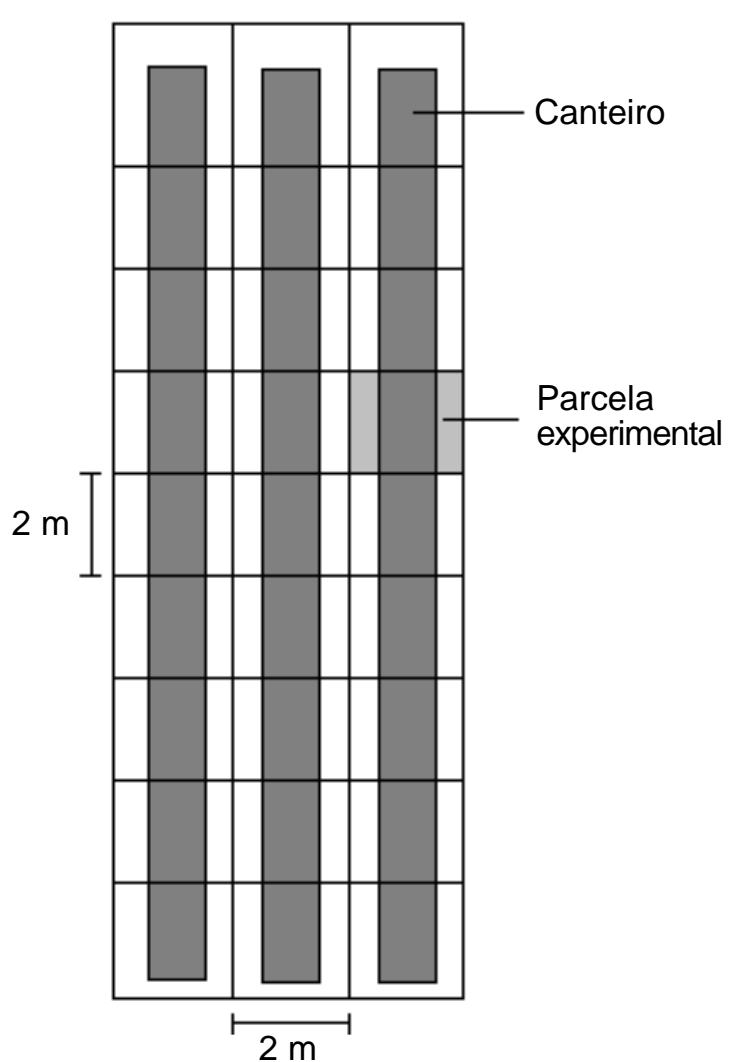

Figura 1 - Esquema da área experimental, demonstrando a disposição dos canteiros e divisões das parcelas.

Os tratamentos foram compostos da combinação de 3 fatores: salinidade da água de irrigação com 3 níveis $\left(\mathrm{S} 1=1,58 ; \mathrm{S} 2=3,08\right.$ e S3 $\left.=5,13 \mathrm{dS} \mathrm{m}^{-1}\right)$, lâminas de água de irrigação com 2 níveis ( $L 0=1,00 \times E T c$ e $L 1=$ $1,25 \times E T c)$, sendo ETc a evapotranspiração da cultura, e freqüências de aplicação da lâmina $\mathrm{L} 1$ com 2 níveis ( $\mathrm{F} 1$ = em todas as irrigações e F2 = quando a lâmina de água de irrigação acumulada em L0 atingia $100 \mathrm{~mm}$ ). Para a freqüência $F 2$, as irrigações foram feitas com base na lâmina L0 e sempre que a lâmina de água de irrigação acumulada no tempo alcançava $100 \mathrm{~mm}$, as parcelas submetidas à lâmina L1 com freqüência F2 eram complementadas com a lâmina que as parcelas $\mathrm{F} 1$ receberam. Como a lâmina total aplicada durante o ciclo da cultura foi de $198 \mathrm{~mm}$ para o tratamento LO, foi realizada apenas uma aplicação de L1 acumulada nos tratamentos $\mathrm{F} 2$, sendo esta aos 75 dias após o transplantio (DAT), quando a lâmina de água de irrigação acumulada em L0 alcançou $103 \mathrm{~mm}$ (Figura 2).

O manejo da irrigação foi realizado com base nas leituras de um tanque de evaporação reduzido, instalado no interior da estufa, entre dois canteiros, e de tensiômetros localizados a 0,15 e $0,30 \mathrm{~m}$ de profundidade, aproximadamente a $0,10 \mathrm{~m}$ de distância da planta e do gotejador. Dessa forma, a lâmina de água de irrigação era calculada com base na evaporação do tanque "Classe A", estimada a partir da evaporação do tanque reduzido, assumindo Kp igual a 1,0 (Martínez-Raya \& Castilla, 1989;

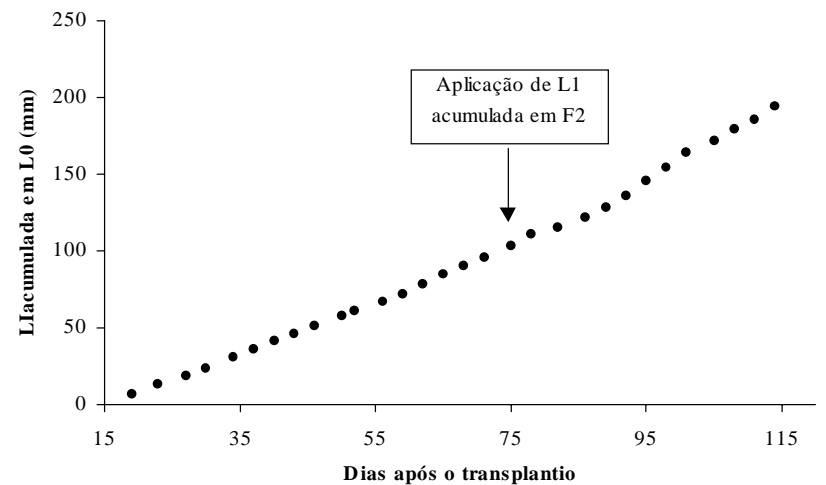

Figura 2 - Lâmina de água de irrigação acumulada em função do número de dias após o transplantio para os tratamentos de lâmina L0, indicando a data de aplicação da lâmina L1 acumulada nos tratamentos de frequência F2.

Castilla et al., 1990), e o ajuste da lâmina era feito pela leitura do tensiômetro mais profundo nas parcelas S1L0. Quando no dia após à irrigação o tensiômetro indicava que a umidade a 0,30 m não havia atingido a capacidade de campo, o Kc para a próxima irrigação era aumentado, resultando no aumento da lâmina de água de irrigação.

O sistema de irrigação utilizado foi o gotejamento, com emissores de vazão média de $4,0 \mathrm{~L} \mathrm{~h}^{-1}$, e um emissor por planta localizado a $2 \mathrm{~cm}$ de distância do caule. Os adubos foram misturados manualmente à água de irrigação em caixas d'água de 500 litros de capacidade.

Os adubos utilizados foram sulfato de amônio $\left[\left(\mathrm{NH}_{4}\right)_{2} \mathrm{SO}_{4}\right]$, nitrato de cálcio $\left[\mathrm{Ca}\left(\mathrm{NO}_{3}\right)_{2}\right]$, ácido fosfórico $\left(\mathrm{H}_{3} \mathrm{PO}_{4}\right)$, nitrato de potássio $\left(\mathrm{KNO}_{3}\right)$, cloreto de potássio $(\mathrm{KCl})$ e sulfato de magnésio $\left(\mathrm{MgSO}_{4} \cdot 7 \mathrm{H}_{2} \mathrm{O}\right)$, sendo que todos os tratamentos receberam $1 / 4$ do $\mathrm{N}$ na forma de amônio e 3/4 na forma de nitrato. Para as águas S2 e S3, além dos adubos, foram adicionados os sais cloreto de sódio $(\mathrm{NaCl})$, cloreto de cálcio $\left(\mathrm{CaCl}_{2}\right)$ e sulfato de magnésio, em proporções adequadas para cada nível de salinidade, de modo que a relação catiônica $(\mathrm{Na}+\mathrm{K}): \mathrm{Ca}: \mathrm{Mg}$ fosse de 5:3:2. O parcelamento da adubação durante 0 ciclo da cultura foi realizado conforme recomenda Papadopoulos (1994).

Foram realizadas determinações da altura das plantas aos 22, 35, 55, 63, 79, 96 e 112 DAT, e da área foliar unitária (AFU) e índice de área foliar (IAF) aos 35, 55 e 63 DAT. No final do período experimental (115 DAT), foram coletadas duas plantas de cada tratamento para medições foliares, como também para a determinação da porcentagem de matéria seca das folhas (MSF).

$O$ delineamento estatístico adotado foi o de blocos casualizados completos, com 3 repetições, e os tratamentos foram arranjados no esquema fatorial $3 \times 3$. $\mathrm{Na}$ análise estatística, a lâmina $\mathrm{L} 1$ foi associada às suas frequências de aplicação, sendo consideradas um único fator. $O$ efeito das diferentes salinidades foi analisado por meio do teste de regressão e das diferentes lâminas pelo teste de Dunnett unilateral. 


\section{RESULTADOS E DISCUSSÃO}

Na TABELA 2 estão apresentados os valores de Kc adotados em cada período do ciclo da cultura, bem como a evaporação do tanque "Classe A" no interior da estufa, estimada à partir da evaporação do tanque reduzido. Os altos valores de Kc são devido ao sombreamento do tanque pelas plantas, tornando necessário o aumento do valor deste coeficiente para que a lâmina de água de irrigação fosse suficiente para repor a evapotranspiração da cultura.

O crescimento das plantas de pepino está apresentado na Figura 3, para cada nível de salinidade da água e lâminas de irrigação. Observa-se que o crescimento das plantas foi contínuo até o $63^{\circ}$ DAT, sendo que a partir desta data o crescimento foi mais lento. Após - $35^{\circ}$ DAT as diferenças de altura entre os níveis de

TABELA 2 - Médias da evaporação do tanque "Classe A" (ECA), valores adotados de $\mathrm{Kc} e$ evapotranspiração da cultura (ETc) para diferentes intervalos de dias após o transplantio.

\begin{tabular}{ccccc}
\hline $\begin{array}{c}\text { Dias após o } \\
\text { transplantio }\end{array}$ & ECA & $\begin{array}{c}\text { Kc } \\
\text { adotado }\end{array}$ & ETc & ETc \\
\hline & $\mathrm{mm} \mathrm{dia}^{-1}$ & & $\mathrm{~mm} \mathrm{dia}^{-1}$ & $\mathrm{~mm} \mathrm{período}^{-1}$ \\
$19-32$ & 2,04 & 0,92 & 1,59 & 22,29 \\
$33-46$ & 1,43 & 1,22 & 1,72 & 24,12 \\
$47-60$ & 1,13 & 1,54 & 1,73 & 24,17 \\
$61-74$ & 1,43 & 1,50 & 2,17 & 30,31 \\
$75-88$ & 1,15 & 1,54 & 1,78 & 24,96 \\
$89-102$ & 1,99 & 1,52 & 2,82 & 39,53 \\
$103-115$ & 1,83 & 1,54 & 2,52 & 32,75 \\
\hline Total $(\mathrm{mm})$ & 152,26 & - & - & 198,14 \\
\hline
\end{tabular}
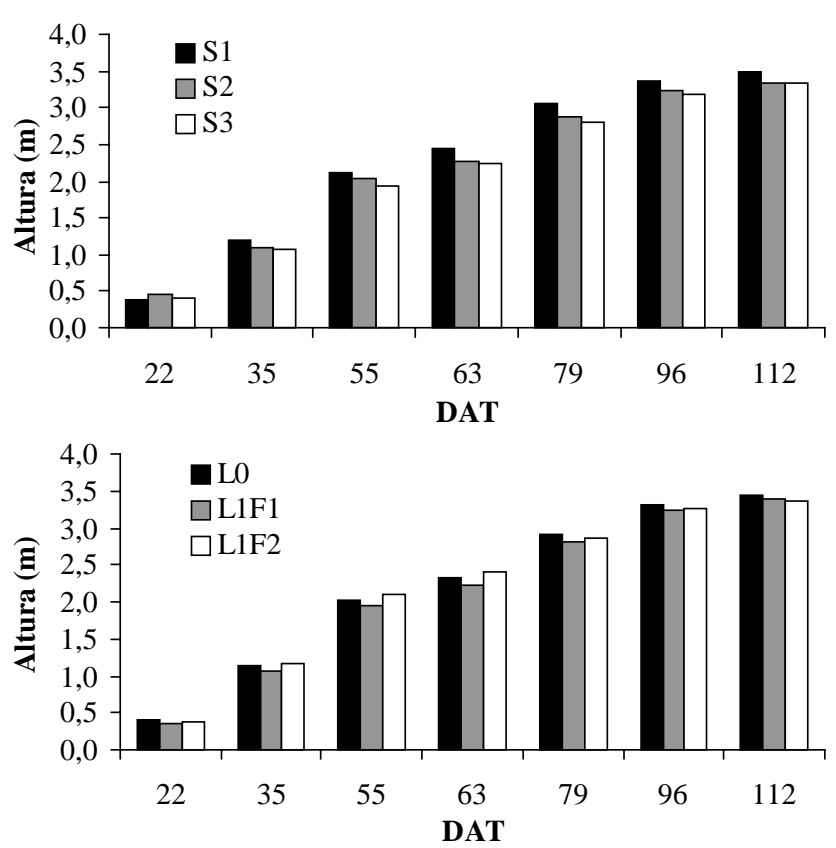

Figura 3 - Altura das plantas de pepino para cada salinidade da água e lâmina de água de irrigação, em função do número de dias após o transplantio (DAT). salinidade aumentaram gradativamente e permaneceram praticamente constantes após o $63^{\circ}$ DAT, com diferenças variando de 4,5 a $7,5 \%$ para a água S2 e 5,0 a $8,7 \%$ para a água $\mathrm{S} 3$, em relação à água $\mathrm{S} 1$. Para as diferentes lâminas de irrigação, nas medições realizadas antes do $35^{\circ}$ e após $079^{\circ} \mathrm{DAT}$, a altura das plantas foi semelhante entre as diferentes frequências de aplicação da lâmina L1. Porém, no período compreendido entre este intervalo de tempo, as plantas submetidas à frequência $\mathrm{F} 2$ apresentaram alturas superiores a $\mathrm{F} 1$, que variaram de 7,0 a $7,5 \%$.

A altura das plantas foi afetada linearmente pela salinidade da água de irrigação nas quatro medições avaliadas, sendo que as diferentes frequências de aplicação de L1 não diferiram significativamente de L0 (TABELA 3). Pode-se observar que a altura das plantas submetidas ao tratamento L1F2 foi maior no início, sendo superado por LO no final do período de cultivo. Portanto, a aplicação de uma quantidade de água $25 \%$ superior àquela necessária para repor a quantidade evapotranspirada, independente da frequência de aplicação, não foi suficiente para promover uma lixiviação eficiente dos sais da região radicular da cultura ao ponto de evitar a redução no crescimento das plantas, causado pelo estresse salino.

Hoffman (1980), utilizando água de irrigação com salinidade de 2,2 dS $\mathrm{m}^{-1}$, submeteu algumas culturas a diferentes lâminas de irrigação, as quais proporcionaram vários níveis de lixiviação que variaram de 0,02 a 0,17. A produção do trigo e aveia cresceram com o aumento da fração de lixiviação $(F L)$ até os níveis de 0,08 e 0,10, respectivamente, a partir das quais a produção se manteve constante. Por outro lado, a estabilização da produção não foi observada para o tomate e alface, ou seja, a produção aumentou linearmente com o aumento da FL, indicando que a FL necessária para estas culturas encontra-se além de 0,17 . Com isso, pode-se verificar que as hortaliças necessitam de uma alta $\mathrm{FL}$, o que, teoricamente, permite a manutenção de níveis mais baixos de salinidade do solo, uma vez que este grupo de culturas apresenta sensibilidade de alta a moderada ao estresse salino.

A água S1 apresentou os maiores valores de AFU, exceto para o $115^{\circ}$ DAT (Figura 4). Por outro lado, o IAF para a água $\mathrm{S} 1$ foi maior em todas as medições. Isso indica que, embora a área foliar média das plantas tenha sido menor na última medição, a área foliar total, a qual representa a capacidade fotossintética total da planta, foi maior para S1 do que para S2 e S3 durante todo o ciclo de cultivo. Para as lâminas de irrigação, observa-se que L1F2 superou as demais após o $63^{\circ}$ DAT. Porém, como a lâmina L1 acumulada foi aplicada aos 75 DAT nos tratamentos de frequência $\mathrm{F} 2$, obviamente, as diferenças observadas não estão relacionadas à maior eficiência de F2 em lixiviar os sais do solo e sim ao maior acúmulo de sais nos tratamentos $L 1 F 1$, visto que este não foi suficiente para evitar a salinização do solo (dados não apresentados). 
A AFU foi afetada linearmente pela salinidade da água de irrigação para a medição realizada aos 55 DAT (TABELA 4). Para o IAF, a salinidade resultou em diferenças significativas para as medições do $35^{\circ}$ e $55^{\circ}$ DAT. Para as diferentes lâminas e frequências, não houve diferenças significativas, embora o tratamento L1F2 tenha apresentado ligeira vantagem em relação aos demais.
As diferenças observadas no IAF entre as águas S1 e S3, para as medições realizadas aos 35,55 e 63 DAT, foram de $16,2,14,2$ e $6,0 \%$, respectivamente, o que pode ser um indicativo de que a cultura é mais sensível à salinidade nos primeiros estágios do desenvolvimento. Com isso, maiores cuidados devem ser tomados nesta fase quanto à qualidade da água de irrigação, a fim de permitir o bom desenvolvimento

TABELA 3 - Resultados da análise de variância e valores médios da altura das plantas para as medições realizadas aos 55 , 63, 96 e 112 dias após o transplantio, para cada salinidade da água e lâmina de água de irrigação.

\begin{tabular}{|c|c|c|c|c|}
\hline \multirow[t]{2}{*}{ Fator } & \multicolumn{4}{|c|}{ Teste $\mathrm{F}$} \\
\hline & 55 & 63 & 96 & 112 \\
\hline - Níveis de salinidade (S) & 3,17 & $5,37^{\star}$ & 3,00 & 3,30 \\
\hline Linear & $6,24^{*}$ & $8,08^{*}$ & $5,25^{\star}$ & $4,97^{\star}$ \\
\hline Quadr. & 0,11 & 2,67 & 0,75 & 1,63 \\
\hline - Lâmina (L)/Frequência (F) & 1,89 & 3,48 & 0,51 & 0,63 \\
\hline \multirow[t]{2}{*}{ - Interação (S x LF) } & 0,47 & 1,62 & 1,12 & 0,90 \\
\hline & \multicolumn{4}{|c|}{ Altura média $(\mathrm{m})$} \\
\hline \multicolumn{5}{|l|}{ - Níveis de salinidade } \\
\hline $\mathrm{S} 1$ & 2,13 & 2,45 & 3,37 & 3,50 \\
\hline S2 & 2,03 & 2,27 & 3,24 & 3,35 \\
\hline S3 & 1,94 & 2,25 & 3,19 & 3,33 \\
\hline \multicolumn{5}{|l|}{ - Lâmina (L)/Frequência (F) } \\
\hline LO & 2,03 & 2,34 & 3,31 & 3,44 \\
\hline L1F1 & $1,93^{\text {ns }}$ & $2,22^{\text {ns }}$ & $3,24^{\text {ns }}$ & $3,38^{\text {ns }}$ \\
\hline L1F2 & $2,11^{\mathrm{ns}}$ & $2,40^{\text {ns }}$ & $3,26^{\text {ns }}$ & $3,35^{\text {ns }}$ \\
\hline
\end{tabular}

* Significativo ao nível de 0,05 de probabilidade pelo teste $\mathrm{F}$.

ns Não significativo ao nível de 0,05 de probabilidade pelo teste de Dunnett unilateral, em relação a L0.
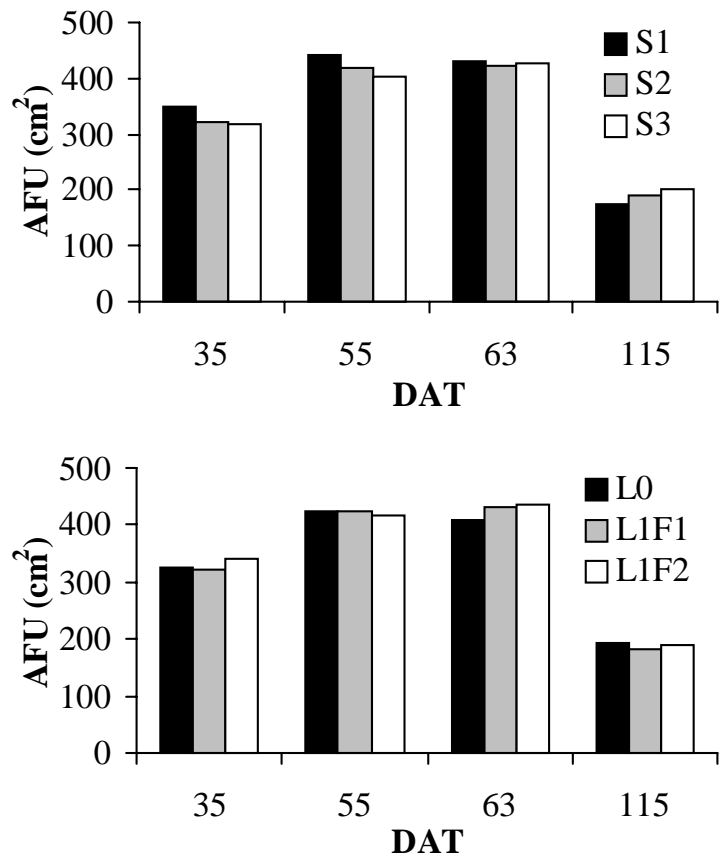
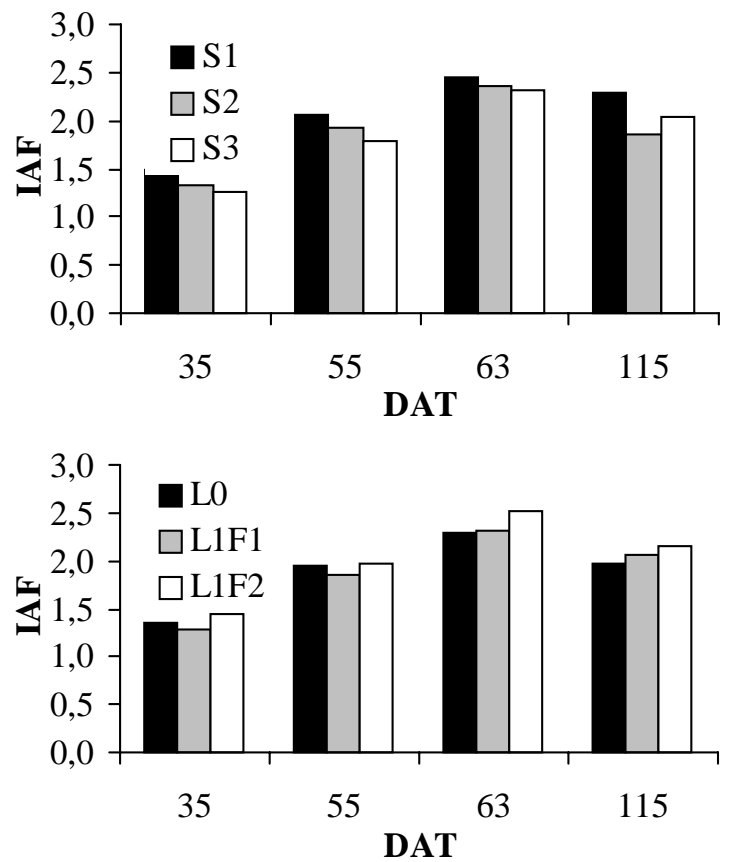

Figura 4 - Área foliar unitária (AFU) e índice de área foliar (IAF) das plantas de pepino para cada salinidade da água e lâminas de irrigação, em função do número de dias após o transplantio (DAT). 
TABELA 4 - Resultados da análise de variância e valores médios da área foliar unitária e índice de área foliar das plantas, medidos aos 34, 55 e 63 dias após o transplantio, para cada salinidade da água e lâmina de água de irrigação.

\begin{tabular}{|c|c|c|c|c|c|c|}
\hline \multirow[b]{2}{*}{ Fator } & \multicolumn{3}{|c|}{ Área Foliar Unitária $\left(\mathrm{cm}^{2}\right)$} & \multicolumn{3}{|c|}{ Índice de Área Foliar } \\
\hline & 34 & 55 & 63 & 34 & 55 & 63 \\
\hline \multicolumn{7}{|c|}{ Teste $\mathrm{F}$} \\
\hline - Níveis de salinidade (S) & 2,48 & $4,64^{*}$ & 0,05 & $3,81^{*}$ & $4,82^{*}$ & 0,36 \\
\hline Linear & 3,62 & $9,07^{* *}$ & 0,02 & $6,87^{*}$ & $9,64^{* *}$ & 0,65 \\
\hline Quadr. & 1,34 & 0,21 & 0,08 & 0,84 & 0,02 & 0,06 \\
\hline - Lâmina (L)/Frequência (F) & 0,80 & 0,23 & 0,77 & 1,31 & 0,80 & 0,97 \\
\hline - Interação (S x LF) & 0,31 & 1,14 & 0,39 & 0,54 & 0,61 & 0,23 \\
\hline & \multicolumn{6}{|c|}{ Valores médios } \\
\hline \multicolumn{7}{|l|}{ - Níveis de salinidade (S) } \\
\hline $\mathrm{S} 1$ & 349,7 & 441,5 & 429,5 & 1,50 & 2,07 & 2,46 \\
\hline S2 & 320,3 & 419,3 & 422,5 & 1,32 & 1,93 & 2,36 \\
\hline S3 & 318,0 & 401,3 & 426,1 & 1,25 & 1,78 & 2,31 \\
\hline \multicolumn{7}{|l|}{ - Lâmina (L)/Frequência (F) } \\
\hline LO & 327,3 & 424,0 & 410,5 & 1,36 & 1,94 & 2,30 \\
\hline L1F1 & $320,4^{\mathrm{ns}}$ & $422,7^{\text {ns }}$ & $431,1^{\mathrm{ns}}$ & $1,28^{\mathrm{ns}}$ & $1,86^{\mathrm{ns}}$ & $2,31^{\text {ns }}$ \\
\hline L1F2 & $340,2^{\text {ns }}$ & $415,5^{\text {ns }}$ & $436,5^{\mathrm{ns}}$ & $1,44^{\mathrm{ns}}$ & $1,97^{\mathrm{ns}}$ & $2,52^{\text {ns }}$ \\
\hline
\end{tabular}

* Significativo ao nível de 0,05 de probabilidade pelo teste $\mathrm{F}$; ${ }^{*}$ Significativo ao nível de 0,01 de probabilidade pelo teste $\mathrm{F}$.

ns Não significativo ao nível de 0,05 de probabilidade pelo teste de Dunnett unilateral, em relação a L0.

vegetativo das plantas, o qual está diretamente relacionado com a produção.

O excesso de sais na solução do solo modifica as atividades metabólicas das células no processo de alongamento celular, limitando a elasticidade da parede celular, reduzindo o alongamento da célula e, como conseqüência, o crescimento da planta. Chartzoulakis (1994), irrigando o pepino com águas de diferentes salinidades, verificou que a área foliar total das plantas reduziu para salinidades da água de irrigação acima de 2,7 dS m ${ }^{-1}$, sendo que, para salinidades acima de 5,0 dS $\mathrm{m}^{-1}$, esta redução foi melhor correlacionada com a redução da expansão foliar do que com o número de folhas. A fotossíntese foi reduzida em $50 \%$ para a salinidade de 5,0 $\mathrm{dS} \mathrm{m}^{-1}$, em comparação com o tratamento menos salino $\left(0,3 \mathrm{dS} \mathrm{m}^{-1}\right)$, enquanto que o crescimento das plantas e o peso seco total foram reduzidos para salinidades acima de $2,7 \mathrm{dS} \mathrm{m}^{-1}$.

A MSF, determinada por ocasião do final do cultivo, encontra-se na Figura 5. Verifica-se que esta aumentou com o aumento da salinidade da água de irrigação, o que também foi observado por Blanco et al. (1999) em folhas de alface e Medeiros (1998) para a cultura do pimentão, em decorrência da baixa pressão de turgor das células, ocasionada pelo estresse salino. Para as diferentes lâminas e frequências, L1F1 apresentou uma MSF inferior às demais, havendo a possibilidade de ter ocorrido uma maior absorção de água e aumento da turgescência, visto que a aplicação de um maior volume de água resultou em maiores teores de umidade no solo.

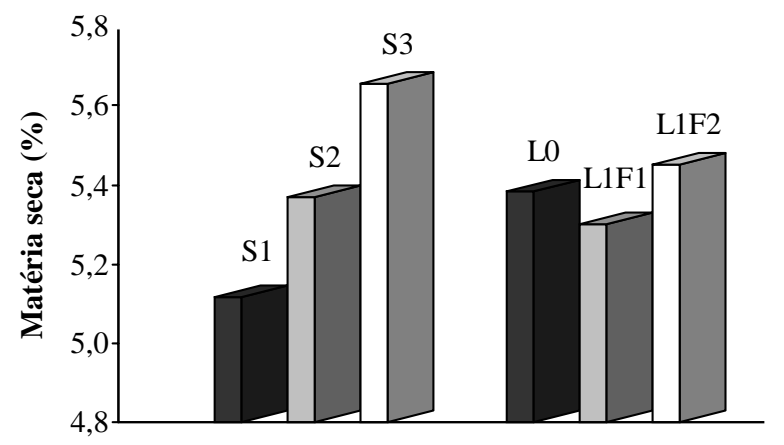

Figura 5 - Porcentagem de matéria seca nas folhas de pepino no final do ciclo de cultivo.

\section{CONCLUSÕES}

A utilização de água salina para irrigação do pepino enxertado em ambiente protegido resultou na redução do desenvolvimento vegetativo das plantas.

A cultura demonstrou maior sensibilidade ao estresse salino nas primeiras etapas do seu desenvolvimento, devendo-se estabelecer medidas que minimizem a exposição da cultura ao excesso de sais nesta fase.

A aplicação de uma quantidade de água $25 \%$ superior àquela necessária para repor o volume de água evapotranspirado não foi suficiente para evitar os efeitos da salinidade.

\section{AGRADECIMENTO}

À Fundação de Amparo à Pesquisa do Estado de São Paulo, pela concessão dos recursos financeiros utilizados no desenvolvimento deste trabalho. 


\section{REFERÊNCIAS BIBLIOGRÁFICAS}

AYERS, R.S.; WESTCOT, D.W. Water quality for agriculture. Rome: FAO, 1985. 174p. (Irrigation and Drainage Paper, 29)

BLANCO, F.F.; FOLEGATTI, M.V. Salinização do solo em ambiente protegido sob fertirrigação. In: WORKSHOP DE FERTIRRIGAÇÃO, 1., Piracicaba, 1999. Resumos. Piracicaba: USP, ESALQ, Depto. Engenharia Rural, 1999. p.3-4.

BLANCO, F.F.; MEDEIROS, J.F.; FOLEGATTI, M.V. Produção da alface (Lactuca sativa L.) em ambiente protegido sob condições salinas. (Compact disc). In: CONGRESSO BRASILEIRO DE ENGENHARIA AGRÍCOLA, 28., Pelotas, 1999. Anais. Pelotas: SBEA/FEA, UFPel, 1999.

CAÑIZARES, K.A.L. A cultura do pepino. In: GOTO, R.; TIVELLI, S.W. (Org.) Produção de hortaliças em ambiente protegido: condições subtropicais. São Paulo: UNESP, 1998. cap.7, p.195-223.

CARRIJO, O.A.; SILVA, W.L.C.; MAROUELLI, W.A.; SILVA, H.R. Tendências e desafios da fertirrigação no Brasil. In: FOLEGATTI, M.V. (Coord.) Fertirrigação: citrus, flores, hortaliças. Guaíba: Agropecuária, 1999. cap.1, p.155-169.

CASTILLA, N.; ELIAS, F.; FERERES, E. Evapotranspiracion de cultivos horticolas en invernadero en Almeria. Investigacion Agraria: produccion y proteccion vegetal, v.5, p.117-125, 1990.

CHARTZOULAKIS, K.S. Effects of saline irrigation water on germination, growth and yield of greenhouse cucumber. Acta Horticulturae, v.287, p.327-334, 1990.

CHARTZOULAKIS, K.S. Photosynthesis, water relations and leaf growth of cucumber exposed to salt stress. Scientia Horticulturae, v.59, p.27-35, 1994.

GORHAM, J. Sodium content of agricultural crops. In: PHILLIPS, C.J.C.; CHIY, P.C. (Ed.) Sodium in agriculture. Canterbury: Chalcombe Publications, 1995. cap.2, p.17-32.

HOFFMAN, G.J. Leaching requirement for salinity control in agriculture. In: INTERNATIONAL SYMPOSIUM ON SALT AFFECTED SOILS, Karnal, 1980. Symposium Papers. Karnal: CSSRI, 1980. p.277-283.

JONES, R.W.; PIKE JUNIOR, L.M.; YOURMAN, L.F. Salinity influences cucumber growth and yield. Journal of the American Society for Horticultural Science, v.114, p.547-551, 1989.
LIMA, R. D'ARC; DIAS, W.P.; CASTRO, J.M.C. Doenças causadas por nematóides em cucurbitáceas. Informe Agropecuário, v.17, p.57-59, 1995.

LOOMIS, E.L.; CRANDALL, P.C. Water consumption of cucumbers during vegetative and reproductive stages of growth. Journal of the American Society of Horticultural Science, v.102, p.124-127, 1977.

MARTÍNEZ-RAYA, A.; CASTILLA, N. Evapotranspiracion del pimiento en invernadero en Almeria. ITEA: Produccion Vegetal, n.85, p.57-62, 1989.

MEDEIROS, J.F. Manejo da água de irrigação salina em estufa cultivada com pimentão. Piracicaba, 1998. 152p. Tese (Doutorado) - Escola Superior de Agricultura "Luiz de Queiroz", Universidade de São Paulo.

MEDEIROS, J.F.; PEREIRA, F.A.C.; FOLEGATTI, M.V.; PEREIRA, A.R.; VILLA NOVA, N.A. Comparação entre a evaporação em tanque Classe-A padrão e em minitanque, instalados em estufa e estação meteorológica. In: CONGRESSO BRASILEIRO DE AGROMETEOROLOGIA, 10., Piracicaba, 1997. Anais. Piracicaba: SBA, 1997. p.228-230.

ODA, M. New grafting methods for fruit-bearing vegetables in Japan. Japan Agricultural Research Quarterly, v.29, p.187-194, 1995.

PAPADOPOULOS, A.P. Growing greenhouse seedless cucumbers in soil and in soilless media. Otawa: Agriculture and Agri-Food Canada, 1994. 126p. (Publication, 1902/E)

PAPADOPOULOS, I. Fertirrigação: situação atual e perspectivas para o futuro. In: FOLEGATTI, M.V. (Coord.) Fertirrigação: citrus, flores, hortaliças. Guaíba: Agropecuária, 1999. cap.1, p.11-154.

STANLEY, C.D.; MAYNARD, D.N. Vegetables. In: STEWART, D.R.; NIELSEN, D.R. (Ed.) Irrigation of agricultural crops. Madison: ASA, CSSA, SSSA, 1990. p.921-950.

TRANI, P.E.; GROPPO, G.A.; SILVA, M.C.P.; MINAMI, K.; BURKE, T.J. Diagnóstico sobre a produção de hortaliças no estado de São Paulo. Horticultura Brasileira, v.15, p.19-24, 1997.

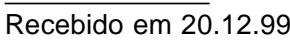

